\title{
PROJETO JABRE E ESTRATÉGIAS DE PRODUCCÃO E CIRCULAÇÃO DE CINEMA NA PARAÍBA ${ }^{1}$
}

\section{JABRE PROJECT AND STRATEGIES OF FILM-MAKING AND CIRCULATION IN PARAÍBA STATE}

\author{
Edmilson Gomes da Silva Junior *
}

\begin{abstract}
Resumo
O artigo visa analisar o projeto JABRE (Laboratório Paraibano para Jovens Roteiristas) a partir de seus resultados, tentando encontrar convergências com estruturas maiores que dizem respeito às formas pelas quais as atividades culturais e de bens simbólicos se organizam em sua interface com a fase atual do capitalismo, e de que modo isso produz novas conformações para a produção cinematográfica contemporânea. A pesquisa foi realizada a partir das edições de 2011 a 2019 do projeto, buscando contemplar, sobretudo, as produções filmicas realizadas como desdobramentos diretos do laboratório, através de informações sobre as condições de realização das obras assim como de dados sobre os circuitos de exibição e suas premiações. Para tal, privilegiaremos dois aspectos principais: produção e circulação. Por meio dessas duas frentes de incursão, almeja-se ter uma maior compreensão do tema, colocando-o em perspectiva a fim de ressaltar convergências e singularidades.
\end{abstract}

Palavras-chave: Laboratório Jabre; Cinema Pós-industrial; Cinema Independente; Produção e Circulação.

\begin{abstract}
The article aims to analyze the project JABRE (Paraiba Laboratory for Young Screenwriters) based on its results, attempting to identify convergences between the ways in which cultural activities and symbolic goods are organized through their interface with the current phase of capitalism and how such interface produces new conformations for contemporary film production. The research was carried out during the 2011 to 2019 editions of the project, seeking to consider, above all, the film productions realized as direct consequence of the laboratory, through information on the conditions for carrying out the works, as well as data on the exhibition circuits and their awards. To this end, we will privilege, above all, two principal aspects: production and circulation. Through these two fronts of incursion, we aim to achieve a greater understanding of the theme, putting it into perspective in order to highlight convergences and also singularities.
\end{abstract}

Keywords: Jabre Laboratory; Post-industrial Cinema; Independent Film-making; Production and Circulation.

\footnotetext{
${ }^{1}$ Parte das discussões trazidas nesse artigo foram originadas da monografia "Do laboratório à autoria: Projeto Jabre e experiência cinematográfica no interior da Paraíba" (SILVA JÚNIOR, 2019), defendida no Curso de Ciências Sociais da UFPB no ano de 2019, sob orientação do professor Aécio Amaral.

* Mestrando em Sociologia pelo Programa de Pós-graduação em Sociologia da UFPB/Brasil. E-mail: edmilson.gomes@academico.ufpb.br.
} 


\section{Introdução}

Criado pelo cineasta Torquato Joel no ano de 2011, então servidor técnicoadministrativo da UFPB, e pela cineasta e professora Virgínia Gualberto, o "Jabre (Laboratório Paraibano para Jovens Roteiristas)" nasce como iniciativa ligada à Próreitora de Assuntos Comunitários (PRAC) por meio da Coordenação de Extensão Cultural $(\mathrm{COEX})^{2}$ da Universidade Federal da Paraíba em parceria com prefeituras municipais $^{3}$, ONG's e o setor privado. O laboratório acontece a partir de oficinas de elaboração de roteiro e apreciação de filmes, contando com consultorias de profissionais e intercalado com trabalhos em grupo e individuais. O laboratório busca incentivar o surgimento de novos realizadores de audiovisual, e é destinado majoritariamente a jovens residentes em cidades interioranas do estado da Paraíba.

Nasce como fruto das ações de dois projetos de extensão universitária já existentes: Torquato Joel já havia criado o Projeto ViAção Paraíba, iniciado em 2007, também ligado à Coordenação de Extensão Cultural (COEX-UFPB), e Virgínia Gualberto coordenava o Projeto Cinestésico ${ }^{4}$ iniciado em 2008 no Centro de Educação da Universidade Federal da Paraíba. Concentrando seus esforços metodológicos a partir de oficinas de formação e apreciação estética da linguagem audiovisual direcionadas para pequenas cidades do estado, esses projetos ainda não objetivavam impulsionar a produção cinematográfica desses jovens interioranos ${ }^{5}$, empenho que foi feito a partir da criação do Laboratório Jabre, que buscou unir tanto a formação quanto o fomento à criação.

\footnotetext{
${ }^{2} \mathrm{http}: / /$ www.prac.ufpb.br/prac/coordenacoes/coex

${ }^{3}$ Prefeitura de municípios paraibanos: Congo, Maturéia, Serra da Raiz, São José de Piranhas, entre outras.

${ }^{4}$ http://projetocinestesico.blogspot.com/

${ }^{5}$ Mesmo com o foco direcionado apenas para a formação, houve já a partir deles um significativo desdobramento, pois sete ex-participantes do Projeto ViAção foram contemplados em 2010 pelo edital do programa "Micro Projetos Mais Cultura", lançado pelo Governo Federal. O resultado foi a produção de seis curtas-metragens e um festival de cinema liderados por jovens do interior: Paulo Roberto de Souza Junior, da cidade de Nazarezinho-PB, dirigiu o curta-metragem Olhar Particular (2011); Kennel Rógis Paulino Batista Nunes, da cidade de Coremas-PB, dirigiu o curta-metragem Travessia (2011); Arnaldo Farias de Freitas, da cidade do Congo-PB, dirigiu o curta-metragem Meu presente precioso (2011); Francisco Andrade Pires Neto da cidade de Coremas-PB, dirigiu o curta-metragem $A$ caixa d'água do sertão (2011); Ighor do Egito, da cidade de Serra Branca-PB, dirigiu o curta-metragem No meu pé de parede (2011); Eduardo Gomes dos Santos, da cidade de Dona Inês-PB, dirigiu o curtametragem Metafísica (2011) e Luciano de Azevedo Silva, da cidade de Monteiro-PB, produziu o Festival do Minuto do Cariri Paraibano também em 2011. Esses resultados figuram como um primeiro ciclo de produção cinematográfica interiorana.
} 
O que vem dando destaque e importância ao laboratório é que, além de contribuir para a interiorização da linguagem cinematográfica, ele também vem buscando estimular uma maior democratização do acesso à produção e circulação de audiovisual para as pequenas localidades do estado. Isso, por sua vez, vem matizando a cena cinematográfica paraibana, nacional e internacional contemporânea a partir de filmes dirigidos/produzidos por jovens de cidades interioranas.

Com uma década de existência, o Laboratório Jabre apresenta um saldo significativo no que se refere ao quantitativo de obras realizadas como resultado direto de suas ações; são cerca de treze produções de curta-metragem, entre ficções, documentários e híbridos, que tiveram o seu roteiro desenvolvido a partir do projeto. Importante salientar também que tais obras possuem qualidade técnica considerável, tendo em vista sua circulação em festivais importantes do país e do mundo e as premiações já recebidas.

Os curtas já realizados até agora são: Fogo pagou (2012) e Aroeira (2016) de Ramon Batista (Nazarezinho-PB); Sophia (2013) de Kennel Rogis (Coremas-PB); Candeeiro (2014) de Adriano Roberto (Juripiranga-PB); Dito (2014) e Ultravioleta (2017) de José Dhiones (Congo-PB); Praça de Guerra (2015) de Ed Junior (Catolé do Rocha-PB); Ilha (2016) de Ismael Moura (Cuité-PB); Manancial (2016) de Bruno Soares (Condado-PB); Stanley (2016) de Paulo Roberto (Nazarezinho-PB); Você conhece Derréis (2017) de Veruza Guedes (Cajazeiras-PB); Atrito (2017) de Diego Lima (João Pessoa-PB); e Caetana (2018) de Caio Bernardo (Coxixola-PB).

É interessante pontuar que esse atual panorama de produção cinematográfica paraibano apresenta algumas inovações, sobretudo do ponto de vista da representatividade regional. Como nos mostra Joel (2014, p.7), ao analisarmos o cenário audiovisual paraibano de décadas anteriores, visando entender a relação existente entre produção/circulação e localidade das obras e dos agentes sociais, se perceberá que há uma predominância desta, de modo quase unânime, aos grandes centros do estado, como João Pessoa e Campina Grande. Inversamente, atualmente vem acontecendo um crescente processo de interiorização da produção audiovisual para diversas regiões do estado, assim como a criação, nessas localidades, de janelas de exibição dessas obras. Há, então, tanto uma produção emergente de cinema como também o surgimento de festivais que permitem uma circulação intra-interiorana das obras, ambos se estabelecendo fora dos espaços já consagrados desse campo no estado. 
Para Silva (2015a), isso se dá, dentre outras coisas, por meio da ação de inúmeros projetos e iniciativas ligados às universidades e/ou organizações não governamentais (o Projeto Jabre aí incluído) que almejaram levar formação, exibição e incentivo à produção de/em cinema para estas localidades. Aliado a isso tem-se, também, um ambiente marcado por uma maior difusão dos meios tecnológicos de captação, edição e propagação de audiovisual que, incorporado ao "potencial" da internet, dariam um caráter pretensamente mais acessível a esse uso, via cinema digital (DE LUCA, 2009).

Em relação à circulação desses filmes há uma configuração interessante a ser analisada: a criação, também nas cidades interioranas, de festivais de cinema e mostras que servem como janelas de divulgação das obras produzidas localmente. Analisando essa realidade, Pinto (2017) busca entender o movimento extremamente frutífero de audiovisual nas cidades do semiárido paraibano a partir, justamente, dessas janelas de exibição, pontuando o protagonismo de jovens cineastas interioranos não apenas como realizadores de filmes, mas também como mobilizadores locais que, na falta de circuitos consolidados de circulação para bens desse tipo, acabam criando estratégias próprias para exibirem suas obras. Ainda segundo o autor, esse processo de interiorização tanto da produção como também da circulação de audiovisual para pequenas cidades, levado a cabo por pessoas (sobretudo jovens) da própria localidade, representa uma excepcionalidade da Paraíba em relação aos demais estados brasileiros.

A presente pesquisa foi realizada a partir das edições de 2011 a 2019 do projeto, buscando contemplar, sobretudo, as produções fílmicas realizadas como desdobramentos diretos do laboratório, através de informações sobre as condições de realização das obras assim como de dados sobre os circuitos de exibição e suas premiações. Para tal, privilegiaremos dois aspectos principais: produção e circulação. Por meio dessas duas frentes de incursão, almeja-se ter uma maior compreensão do tema, colocando-o em perspectiva, encontrando possíveis pontos de encontro que aproximem essa produção e difusão interiorana de cinema na Paraíba a contextos mais amplos que o ligam ao atual estágio do capitalismo e a discussões sobre cinema independente contemporâneo. 


\section{Do fordismo ao capitalismo flexível: o cinema pela ótica do "pós-industrial"}

É consenso que a partir da década de 1970 houve mudanças de grande intensidade no seio do capitalismo, no interior das quais este se transmuta de um modelo fordista para um regime de acumulação mais flexível. Essas mudanças que afetaram o modo de produção e acumulação do sistema capitalista fizeram emergir novos rearranjos; o foco afasta-se da preocupação apenas com a eficiência produtiva em larga escala visando, em última instância, o produto, e se aloja em processos cognitivos mais amplos, o que acaba moldando a nova lógica do capitalismo que passa então a se exercer, sobretudo, no domínio da cultura, que se integra e dita a produção de mercadorias em geral a partir de um cenário que se convencionou chamar de "pós-industrial" (HARVEY, 2004).

Enxergar essa atual condição do capitalismo a partir de um viés cultural e simbólico traz novas definições e abordagens para o campo da estética e da arte. A nova face capitalista da flexibilidade também submerge os modelos de produção artística, causando transformações nos modos de criação, produção e circulação de obras, resultando em um cenário de possibilidades múltiplas potencializadas, por exemplo, pela ascensão de novas tecnologias, pela criação de redes de circulação e consumo intensos que garantem um maior fluxo de troca de informação e também pela formação de ajuntamentos e coletivos artísticos que pensam em modos alternativos de produção. Nessa esteira, a alcunha de "pós-industrial" também é apropriada, por exemplo, pelo cinema (MIGLIORIN, 2011), e dá conta de evidenciar um conjunto de novas práticas que vêm sendo desenvolvidas à revelia de modelos industriais mais convencionais.

Nascido no início do século XX, o fordismo consolidou-se como um modo de produção em massa de mercadorias voltado para a eficiência, e pensado para atender a grandes demandas. Esse sistema de produção de massas buscava suprir um mercado de consumo também massificado em uma nova realidade forjada a partir das revoluções do século XIX, sobretudo a industrial. Consolidado durante o pós-guerra, quando este se alinha ao keynesianismo, o sistema fordista torna-se política de Estado, o que garantiu uma série de investimentos públicos em setores como transporte e construção civil, garantindo pleno emprego e amparando o consumo em massa, o que fez com que o regime vivesse um período de relativa estabilidade nos países capitalistas por mais de três décadas. 
Assim, surgido no seio de uma sociedade marcada pela ascensão do fordismo, o cinema também incorpora essa lógica industrial em seu processo de produção, e, mesmo com pouquíssimo tempo de criação, já se consolida enquanto produto de massas, seguindo uma lógica de mercado voltada para o entretenimento a partir da qual já, nas primeiras décadas do século XX, tinha nos Estados Unidos o seu monopólio. Voltadas majoritariamente para a produção de longas-metragens, grandes empresas deram conta dessa produção e, algum tempo depois, também da distribuição desses produtos, o que representou um negócio bastante rentável em vista de sua boa recepção pela grande massa. Existindo exclusivamente por intermédio da reprodutibilidade, é essa a sua face que será explorada e encontrará forte amparo industrial:

\footnotetext{
Outro fator que possibilitou a implantação do cinema como arte dominante é uma característica técnica: o fato de se poder tirar cópias. [...] Esse sistema de cópias permitiu rápida e brutal expansão do mercado mundial de cinema e a dominação da quase totalidade do mercado internacional por umas poucas cinematografias (BERNARDET, 2000, p. 132).
}

No que se refere aos custos de produção da época, em grande medida, o cinema não figurava como arte acessível e de baixo orçamento. Com equipamentos de captação e de edição e montagem bastante caros, as produções cinematográficas exigiam, por exemplo, uma maior especialização técnica e envolvimento de grandes equipes em todo o processo. Esse panorama começou a se modificar nas décadas finais do século XX, quando inovações tecnológicas tornaram esse ambiente mais matizado em termos de possiblidades de maior acessibilidade à produção cinematográfica, barateando gastos e democratizando o acesso (ROLIM, 2017, p. 39).

Esses avanços na área da tecnologia aconteceram em consonância com arranjos econômicos e sociais maiores que demarcaram um processo de transição do modelo capitalista, a começar pelos contornos diferenciados de modos de produção/acumulação e das relações de trabalho. Como marca desse novo momento, temos, por exemplo, uma redução drástica de empregos regulares em detrimento de um aumento de subcontratações e trabalhos temporários, precarização de direitos trabalhistas e perda de força do movimento sindical. Por outro lado, como já apontado no caso específico do cinema, também ocorreram processos cada vez mais rápidos de inovação tecnológica, tornando o acesso à informação e a novos dispositivos eletrônicos e digitais mais facilitado. Tudo 
isso ocorreu, vale lembrar, a partir de mudanças de natureza global que marcaram o declínio do modelo fordista tradicional.

As leituras e interpretações dessa nova etapa são as mais diversas possíveis, emergindo posições das mais antagônicas, indo desde teóricos que buscam encontrar nesse período de transição não mais que as continuidades com o modelo capitalista tradicional (HARVEY, 2004), ou buscando nesse cenário não mais que as consequências da própria modernidade (GIDDENS, 1991), até chegar àqueles que atestam criticamente o fim da modernidade clássica e o advento de um novo tipo de configuração social a que se deu o nome de "Pós-Modernidade" (JAMESON, 2007).

Em meio a esta ampla discussão, o que nos interessa aqui é procurar compreender de que forma essas transformações nos modelos de produção do capitalismo provocaram mudanças nas práticas culturais que fizeram com que elas se rearranjassem em um cenário de maior visibilidade e importância dentro da sociedade. A partir disso, interessa-nos entender como essa configuração pode ser pensada utilizando como campo de análise o cinema contemporâneo.

De fato, o cinema se apresenta como um espaço privilegiado para se perceber essas nuances da contemporaneidade. Afetado também pelas transformações que se seguiram a partir das décadas finais do século XX, há uma série de inovações que afetam desde os modos de captação e reprodução (que acontece na esteira das inovações tecnológicas) e chegam aos modelos de divisão do trabalho e organização do fazer cinematográfico. O que caracterizava o cinema em sua fase inicial de forte aderência à indústria era, em grande medida, os grandes custos que tornavam a sua prática uma atividade restrita.

Contudo, nessa fase atual marcada pela ascensão de novos atores muito por conta da maior facilitação aos meios de fazer cinema, temos um ambiente marcado pela acessibilidade, o que já marca um contraponto interessante em relação à época anterior:

O cinema industrial era pautado pela escassez, o pós-industrial pela abundância. O que temos visto em todo o país é uma produção que vem fazendo uso de uma capacidade material instalada em que a escassez não pauta mais as relações de produção. [...] Na indústria, poucos detêm os meios, muitos se despem de suas potências criativas e a massa consome. O que acontece hoje é que essa multidão que é consumidora e produtora, dispersa e incontrolável, não pode e não deve ter a indústria como norte. Ou seja, o que ela produz e consome ganha valor na circulação e no acesso abundante em um ambiente em 
que os meios técnicos, criativos e de acesso estão disponíveis. (MIGLIORIN, 2011, online).

Essa nova configuração a que Migliorin (2011) nomeia de "Cinema Pósindustrial" também traz outros parâmetros para pensarmos no comércio e circulação das obras, tornando-as mais flexíveis e menos engessadas se comparadas ao modo industrial convencional que funcionava a partir da divisão marcada de tarefas como nos fala Bernardet (2000, p. 135): "Assim a indústria e o comércio cinematográficos foram paulatinamente estruturando-se em três níveis: o produtor, o exibidor e, entre os dois, o distribuidor que serve de intermediário; o que circula nesses níveis nunca é uma mercadoria concreta, sempre direitos." O que temos agora é um patamar no qual a circulação desse novo tipo de cinema acontece em paralelo à indústria, marcado pela abundância, e sendo distribuído através de plataformas digitais com pouquíssimo ou nenhum custo envolvido, e amparado por uma série de espaços alternativos de exibição e divulgação, como mostras, festivais e cineclubes.

Um outro contraponto interessante em relação ao cinema industrial se dá a partir dos modos de produção, os quais, fugindo do modelo de "linha de montagem" tradicional/industrial, apresentam-se a partir de uma outra lógica, marcada por modos alternativos de compor equipe, em que duas ou mais funções são assumidas por uma única pessoa (a exemplo do diretor que muitas das vezes também é roteirista, produtor e distribuidor do seu filme). Finalmente, deve-se considerar o motivo pelo qual essas equipes se unem, pois elas, em geral, levam em consideração não apenas o retorno financeiro, mas, sobretudo, o viés afetivo e coletividade (ROLIM, 2017).

A respeito do último ponto elencado, outro aspecto que merece destaque é a incidência de modelos colaborativos de produção e organização de cinema alternativos aos moldes industriais convencionais. Os chamados coletivos (MIGLIORIN, 2012) são ajuntamentos agregadores de pessoas em prol de uma causa específica que vêm conseguindo produzir e difundir bens culturais a partir de equipes mais enxutas e com baixíssimos (ou nenhum) orçamentos. Esses novos modos de cooperação, no campo artístico, deram conta de alojar, dentre outros grupos, tanto a produção como a distribuição de bens simbólicos gestados em locais longe dos grandes centros urbanosindustriais (BENTES, 2012). 
Ao mesmo tempo, sua composição e seu contexto de existência possuem um ethos semelhante àquele preconizado pelo capitalismo flexível (MICHETTI, 2017) partilhando de uma mesma lógica de horizontalidade, trabalho em rede, flexibilidade do tempo, dentre outros. Contudo, mesmo que haja um compartilhamento do léxico que possa aproximar o modo de ser dos coletivos de modelos de flexibilidade que dizem respeito à nova modalidade do capitalismo, é preciso entender que, a depender do contexto, essas similaridades se dão de maneira desigual e assimétrica ao redor do globo. Isso abre margem para uma dupla interpretação: de um lado deve-se buscar correlações possíveis, mas, ao mesmo tempo, entender a especificidade da localidade.

Por meio dessas novas características o cinema contemporâneo vem se construindo, também a partir de uma postura mais política e de demarcação de espaço marcada pela construção de coletivos e iniciativas que buscam tornar as práticas criativas em audiovisual mais democráticas, e fazer com que elas se estruturem de maneira independente em relação à grande indústria, tanto no que concerne aos modelos alternativos de produção quanto às temáticas e estética dos filmes. De todo modo, a categorização do que é "cinema independente" pode variar também, de acordo com o período e, no caso brasileiro, remontando desde os primórdios da atividade cinematográfica no país. De natureza relacional, o termo pode tornar impreciso um maior delineamento de suas fronteiras, e chega também ao contemporâneo carregando algumas problematizações e matizes que contrastam com o modo industrial convencional.

\section{Da política à garagem: o encontro do cinema "independente" com o contemporâneo}

É durante as décadas de 1940 e 1950 que as primeiras ideias sobre cinema independente começam a despontar no cenário nacional brasileiro. Em um panorama em que a produção cinematográfica se concentrava em grande parte no Sudeste do país, de onde também começavam a despontar os grandes estúdios, como o Vera Cruz e Multifilmes, é de lá que nascerão os primeiros debates sobre "cinema independente". A noção de "independência" poderia, então, ser mobilizada a partir de, pelo menos, dois segmentos: (i) independência em relação à indústria (sinônimo de imperialismo), à qual deveria oferecer um contraponto por intermédio de produções nacionais, e (ii) independente em relação ao conteúdo, apresentando temáticas esteticamente férteis e que 
evidenciassem um conteúdo de relevância para o país, e que fugisse do mero entretenimento.

Desde o início, a demarcação do que de fato seria um "cinema independente" tornou-se algo impreciso e ambíguo. Envolto em disputas entre produtores, distribuidores e exibidores, a delimitação e abrangência do termo foi se formando de acordo com o interesse mobilizado. Se na época, temos de um lado, por exemplo, os cineastas ligados ao Partido Comunista Brasileiro (a exemplo de Nelson Pereira dos Santos) que militavam por uma ideia de cinema independente a partir de uma posição mais ideológica que buscava afastar-se de qualquer concepção industrial por achá-la perniciosa aos interesses da nação e partir dos temas abordados, por outro, temos a ideia do "produtor independente" que, desligado de modo formal da grande indústria, buscava nela, a partir de uma inserção diferenciada, legitimar o seu trabalho de modo mais autônomo, no qual independia qual fosse o tema abordado, contanto que se desse nos moldes daquela forma menos engessada da indústria convencional.

A ambiguidade de parte dos cineastas independentes da época se dava justamente em relação à indústria, pois, ao passo que havia uma dura crítica a esta, de modo contrário também havia, por parte de muitos, um esforço genuíno por um processo de industrialização do cinema brasileiro, emancipado e com mais influência no país do que a produção estrangeira, principalmente a da norte-americana. É interessante notar que esse esforço se dá a partir de conjunturas políticas e sociais maiores. Lembremos que os anos 1950 também figuram como ápice da ideologia desenvolvimentista da indústria brasileira, marcado por um forte sentimento de nacionalismo. Assim, a crítica dos independentes se dirigia à indústria, mas a almejava ao mesmo tempo, a fim de que houvesse uma espécie de "cinema independente industrial brasileiro" (GALVÃO, 1980, p. 21).

É a partir do Cinema Novo que começa a florescer de maneira mais substancial a noção de "independente" no cinema brasileiro. A ideia de independência no cinema já aparecia de maneira marcante, desde a década de 1959, nos cineastas franceses da "Política dos Autores", pois estes davam ênfase ao autor/diretor frente aos demais atores do processo de produção do filme, quanto mais este pudesse expressar suas ideias e convicções com maior liberdade, mais o seu filme tornar-se-ia independente frente à indústria: "Neste caso, a 'independência' que se reivindica para os filmes diz respeito à 
liberdade de autoria dentro das empresas. Não se põe em xeque o sistema de produção empresarial, mas apenas a sujeição dos 'autores' à empresa". (GALVÃO, 1980, p. 16). Essa atitude foi ainda mais acentuada por Glauber Rocha e os demais "cinemanovistas", que deram à noção de "independente" uma posição mais radicalizada, que modifica justamente o caráter de sujeição do autor à indústria.

Contudo estar fora do arcabouço industrial também significava não ter acesso a equipamentos sofisticados nem a bons estúdios. Nesse sentido, manter-se sobre o rótulo de independente à indústria era quase um sinônimo de pouca qualidade técnica. A respeito da precariedade do cinema independente, é interessante a abordagem trazida pelo Cinema Novo, por meio da qual essa característica da falta e da carência em relação aos métodos de produção foi ressignificada, e passou a compor um atributo estético de pertença e sinônimo de militância política do movimento. $\mathrm{O}$ aspecto da precariedade técnica dos filmes serviria como denúncia e analogia em relação às precariedades sociais existentes à época no Brasil. O ethos dessas ideias foi colocado no manifesto intitulado "Eztetyka da Fome”, publicado no ano de 1965, de autoria do cineasta Glauber Rocha.

Por mais atípico que possa parecer, é na época da ditadura civil-militar que o esforço do Estado em industrializar o cinema brasileiro acontece com maior dedicação. Em 1966, cria-se o Instituto Nacional de Cinema, e em 1969, em numa época de recrudescimento do regime, cria-se a Embrafilme (Empresa Brasileira de Filmes S.A), iniciativa de maior destaque na época. Essas ações do governo não se deram de maneira aleatória, e vieram com a finalidade de tentar se contrapor aos filmes do Cinema Novo, que gozavam de prestígio no cenário internacional de exibição. Na década de 1990, a Embrafilme é extinta pelo governo Collor, o que resultou em anos difíceis para o cinema brasileiro:

Em 1990, Fernando Collor, com a prerrogativa de que as questões relacionadas à cultura deveriam ser resolvidas no âmbito do mercado, extinguiu a empresa, juntamente com a própria Lei Sarney, o Concine e a Fundação do Cinema Brasileiro, e ainda desregulamentou a atividade cinematográfica no país, suprimindo mecanismos de proteção como as cotas de tela e abrindo o mercado sem restrições para a entrada do produto estrangeiro. Isso deu início a um período que ficou conhecido como o "apagão" ou a "idade das trevas" do cinema brasileiro (OLIVEIRA, 2016, p. 30-31).

A contrapartida dada pelos cineastas a essas medidas neoliberais do governo Collor ficou conhecida como o período da "retomada", iniciado ainda na primeira metade 
dos anos 1990, e marcado por uma tentativa de reorganização da indústria cinematográfica brasileira. Temendo represálias e rejeição, o governo Collor cria algumas iniciativas para tentar subsidiar a produção cultural do país, a exemplo da Lei Rouanet (Lei número 8.313, de 1991). Dois anos depois é promulgada a Lei do Audiovisual (Lei número 8.685) que oferecia estímulos e subsídios específicos para o setor.

De modo geral, esse período é marcado por uma espécie de "euforia" que culmina em 2001 com a criação da Ancine (Agência Nacional do Cinema) no governo Fernando Henrique Cardoso, pactuando uma espécie de reaproximação entre o Estado e a classe cinematográfica, que acontece em consonância com uma maior preocupação de estados e municípios em oferecer apoio e financiamento a iniciativas na área do audiovisual, abrindo margem tanto para propostas inovadoras, quanto para a criação de nichos de mercado ligados a grandes empresas (a exemplo da criação da Globo Filmes nessa mesma época).

É a partir da medida provisória (MP N $2.228-1$, de 06/09/2001) que, dentre outras coisas, estabelece os princípios gerais da Política Nacional do Cinema, e cria a Agência Nacional do Cinema (ANCINE), que temos a conceituação atual do que de fato caracteriza o cinema como independente, já no seu artigo primeiro:

IV - obra cinematográfica e videofonográfica de produção independente: aquela cuja empresa produtora, detentora majoritária dos direitos patrimoniais sobre a obra, não tenha qualquer associação ou vínculo, direto ou indireto, com empresas de serviços de radiodifusão de sons e imagens ou operadoras de comunicação eletrônica de massa por assinatura (BRASIL, 2001).

Desse modo se concebe "independente" como qualquer obra criada fora do "meio de comunicação de massa". É assim que essas discussões chegam à atualidade, permeadas pela antiga disputa e esforço em se construir enquanto arte autônoma em relação à grande indústria, mas também matizada por novas particularidades, seguindo uma tendência que se mostra marcante desde os primórdios de sua existência: a dificuldade na conceituação e no balizamento do termo. A ideia de cinema independente pode ser mobilizada contemporaneamente, por exemplo, tanto para filmes como $O$ som ao redor, do pernambucano Kleber Mendonça Filho, que contou com orçamento de quase dois milhões de reais, além da venda e exibição em diversos países (inclusive o Brasil, onde teve saldo promissor de expectadores), como também pode ser usado para produções menores, a 
exemplo da estudada aqui, que contam com quase nenhum recurso para produção ou incentivo à circulação.

É desse modo que o cinema independente chega ao contemporâneo, permeado por antigos dilemas, mas também marcado por novos contornos que vêm se consolidando desde os anos 2000. Essa nova leva de cineastas independentes é majoritariamente composta por jovens residentes geralmente em capitais ${ }^{6}$ do país e que contam com pouquíssimo ou nenhum orçamento para viabilizar suas propostas, levando-os a buscarem meios alternativos que passam por modelos diferenciados de composição de equipe e pela formação de coletivos que buscam, mesmo em um cenário escasso de recursos, dar vazão a uma série de produções marcadas tanto pela qualidade técnica ${ }^{7}$, como também pelas temáticas e estéticas dos filmes vinculadas de modo mais autônomo (dada a posição de liberdade em relação à indústria) ao gosto do diretor e/ou equipe.

Esse cenário tem sido captado por alguns estudiosos que tentam dar conta de buscar entender e explicar esses novos rearranjos de produção cinematográfica contemporânea, fazendo isso também a partir de novas nomenclaturas e categorias de entendimento. Assim, Ikeda e Lima, por exemplo, denominam como "Cinema de Garagem" essa nova cena promissora de cineastas:

Com o termo, queremos apontar para outros modos de produção, para além do
"cinema industrial". Com a acessibilidade das novas tecnologias digitais, é
possível, com uma câmera portátil e com um software de edição, fazer e montar
filmes em nossas próprias casas, nas nossas próprias garagens. [...] Esse termo
também problematiza as fronteiras entre o "amador" e o "profissional", que
cada vez mais estão borradas. Essas diferenças não estão tão propriamente
marcadas no campo da técnica (a tecnologia está cada vez mais acessível), mas
sobretudo por uma postura ética do artista, que volta sua produção
essencialmente não para o mercado (para o reconhecimento artístico ou para a
renda de bilheteria), mas sim para uma vocação de expressão mais
propriamente pessoal (IKEDA; DELLANI, 2012, p. 9).

Nesse sentido, a metáfora da "garagem" surge aqui não como sinônimo de amador ou desimportante; ela simboliza, principalmente a ideia de algo mais coeso, enxuto,

\footnotetext{
${ }^{6}$ Mostraremos adiante que essa limitação geográfica no que se refere à produção cinematográfica tem sido matizada a partir de iniciativas que buscam descentralizar o acesso à linguagem audiovisual para cidades interioranas e, a partir disso, tem surgido um cenário de produção cinematográfica alternativo às capitais e grandes centros.

${ }^{7} \mathrm{O}$ que por si já representa um contraponto interessante para esta nova fase, tendo em vista que em décadas anteriores, a "qualidade" só era conseguida a partir de uma vinculação com a grande indústria que dispunha de aparatos tecnológicos mais aperfeiçoados que garantiriam um filme mais bem acabado.
} 
marcado pela cumplicidade e reciprocidade dos que dela participam e que agem em prol da coletividade e pela convicção acerca de um tipo de arte mais autônoma. Na "garagem", dada a sua pequenez espacial frente aos modelos mais comerciais, cabe apenas poucas pessoas, amigos, colegas que comporão a equipe e desempenharão múltiplas funções; a extensa linha de montagem fordista típica do cinema industrial não poderia se alojar nesse compacto cômodo.

\section{Laboratório Jabre e estratégias de produção e circulação de audiovisual contemporâneo na Paraíba}

É pensando nessa disposição da estratégia que buscamos entender aqui o cinema contemporâneo, especificamente a sua composição mais independente, tratada ao longo do texto como "pós-industrial" ou "de garagem". Espera-se que o/a cineasta incorpore em sua prática um determinado comportamento que o leve a procurar táticas das mais diversas para conseguir viabilizar a sua proposta. Essas estratégias podem ir desde a criação de coletivos que funcionam a partir de uma lógica de auxílio mútuo, no qual os membros se revezam entre as produções, desempenhando funções as mais diversas em troca da mesma ajuda para a produção de seus filmes; ou também a partir de financiamentos coletivos, ou da simples "brodagem". 8

Em um cenário mais amplo, essas táticas são pensadas em conformidade com uma realidade quase sempre pautada por baixíssimos orçamentos. No que se refere à produção dos filmes realizados a partir do Laboratório Jabre, nota-se que as estratégias de produção e circulação adotadas por esses jovens interioranos também guardam muitas semelhanças com esse novo tipo de cinema.

Analisando aqui algumas das produções cinematográficas realizadas a partir do laboratório, percebe-se uma confluência no que diz respeito aos modos de produção arranjados para viabilizar os filmes. Dos curtas já existentes, grande parte não contou com nenhuma espécie de recurso proveniente de financiamento público ${ }^{9}$ ou privado que

\footnotetext{
${ }^{8}$ Termo utilizado no cinema para evidenciar um modo de produção no qual a equipe trabalha com pouca ou nenhuma remuneração levando em consideração elos afetivos, sem apelo comercial ou lucrativo.

${ }^{9}$ Dessas obras, algumas delas conseguiram financiamento público via editais, a exemplo dos curtas Praça de guerra, de Edmilson Gomes, e Aroeira, de Ramon Batista, que foram contemplados pelo Fundo de Incentivo à Cultura Augusto dos Anjos do Governo da Paraíba; e Sophia, de Kennel Rógis, contemplado pelo Edital Linduarte Noronha, também do Governo da Paraíba.
} 
cobrisse todos ou grande parte dos custos de produção, o que leva esses jovens a pensarem em modos alternativos para conseguirem transformar seus roteiros em filmes: "Alguns jovens roteiristas, entusiasmados com a ideia de realizar seus curtas, criaram mecanismos de produção, seja através da camaradagem, da 'brodagem' que ocorre nas ações entre amigos [...] ou de solicitações junto ao comércio (e) à prefeitura [...].” (SILVA, 2015b, p. $10)$.

Esse entusiasmo acontece em grande medida pelo apoio dado por parte da coordenação do projeto no intuito de oferecer um mínimo de estrutura para a produção dos filmes. Assim, de um lado, o jovem participante do laboratório que queira realizar o seu curta-metragem articula uma produção local, viabilizando estrutura de hospedagem e alimentação durante os dias de locação e, do outro lado, em contrapartida, os coordenadores do Jabre oferecem alguns equipamentos de captação de imagem e som, e articulam pessoas para compor a equipe técnica, que trabalharão de modo voluntário durante o processo. Foi feita nesses moldes, por exemplo, a produção do filme Manancial (2016), dirigido por Bruno Soares de Condado-PB; o jovem foi um dos vencedores da edição do laboratório em 2015, e no mesmo ano ele começou a pensar em estratégias de produção locais para que o filme pudesse ser realizado. Sobre este processo ele nos conta:

Tudo foi na "guerrilha cinematográfica", termo utilizado pelo próprio Torquato Joel [...]. Para realizar a produção de Manancial a gente ainda conseguiu uma parceria com a prefeitura para alimentação [...] foi difícil conseguir, eu tive que correr atrás na prefeitura, conversei com o vice-prefeito, que demonstrou interesse, a gente falou pra ele na possibilidade de exibição e claro, divulgando o nome da cidade [...] A gente estava com o mínimo mesmo para poder realizar o filme, eu ainda passei em alguns supermercados pedindo contribuição [...] Foi algo muito árduo para a gente conseguir realizar. (informação verbal) ${ }^{10}$.

O termo "cinema de guerrilha" surge aqui como uma nomenclatura usual e incorporada ao discurso para representar um modo muito específico de produção, marcado pela persistência da equipe para produzir obras audiovisuais mesmo em um cenário de extrema carência de recursos, evidenciando um ímpeto de resistência e de batalha (daí o termo "guerrilha") frente às condições materiais bem demarcadas. A expressão também abarca um posicionamento de valorização do cinema enquanto arte

\footnotetext{
${ }^{10}$ Informação fornecida por Bruno Soares em entrevista feita por mim em 15 de março de 2019.
} 
engajada, a partir do seu conteúdo que, em grande medida, afasta-se consideravelmente da indústria de massa.

Esse termo também é utilizado por Veruza Guedes, diretora de Você conhece Derréis? (2017), e José Dhiones, diretor do curta Ultravioleta (2017). Para a produção do seu filme, este último conseguiu mil reais por meio de financiamento coletivo via plataformas online, recurso que foi empregado para bancar despesas com alimentação da equipe, os demais custos foram viabilizados a partir de parcerias com a prefeitura da cidade do Congo-PB e comerciantes locais:

\begin{abstract}
Como o roteiro foi desenvolvido no Laboratório do Jabre, então as parcerias foram feitas com a UFPB, na questão do transporte pra trazer a equipe que foi toda voluntária, como é caracterizado o cinema na Paraíba né, o cinema "de guerrilha", e as parcerias foram com a universidade com a questão do ônibus, com o projeto mesmo, com a pousada aqui do Congo para hospedar todas essas pessoas que viriam voluntariamente pra realização do filme. A alimentação foi feita com esse dinheiro do financiamento que eu dispunha, foi feita na casa de minha mãe, pra toda a equipe (informação verbal). ${ }^{11}$
\end{abstract}

O processo de produção de "Derreis", ele foi "na guerrilha" mesmo, a galera abraçou o projeto, foi uma equipe muito pequena [...] eram pessoas muito amigas e se doaram porque a gente não conseguiu nenhum financiamento, edital, nada disso. [...] Consegui um apoio mínimo pra hospedagem e alimentação da equipe e cada um doou seus próprios equipamentos [...] A produção foi assim, um pouco sofrida, mas na garra (informação verbal). ${ }^{12}$

Nesse sentido, a partir desses relatos, pode-se perceber que as parcerias aparecem aqui como componentes importantes para que esses filmes consigam ser produzidos. Basicamente, elas se estabelecem a partir de dois lugares: o primeiro acontece entre o jovem participante do laboratório e a coordenação do projeto, que, por sua vez, também estabelece parcerias com outros agentes, como produtoras de cinema (que em contrapartida pedem uma cota/porcentagem caso o filme chegue a ganhar alguma premiação em dinheiro) e a própria universidade; o segundo modo de colaboração se dá entre o jovem e a sua cidade, aí é essencial a sua capacidade de articulação/estratégia para conseguir apoio tanto das prefeituras e de outros agentes locais, como comerciantes, vereadores e empresários da cidade, a partir do que podem conseguir algum recurso em dinheiro ou estrutura, como hospedagem e alimentação.

\footnotetext{
${ }^{11}$ Informação fornecida por José Dhiones em entrevista feita por mim em 14 de abril de 2019.

${ }^{12}$ Informação fornecida por Veruza Guedes em entrevista feita por mim em 15 de abril de 2019.
} 
Entretanto, é interessante pontuar que essas parcerias em nível local nem sempre acontecem, o que pode tornar o processo de produção ainda mais difícil. O jovem Caio Roberto, residente na zona rural da cidade de Coxixola-PB e diretor do curta Caetana (2018), fala que não contou com nenhum apoio da prefeitura de seu município, e, para assegurar a produção do seu filme, teve que se valer de outras táticas como a venda de bens pessoais para conseguir levantar recursos:

\begin{abstract}
O apoio aqui a gente não teve quase, sabe, acho que no comércio local da cidade eu consegui foi cinquenta reais, aí tipo eu andei por fora, aí fui em Santa Cruz que tem um comércio mais avulso e consegui com amigos cerca de quatrocentos a quinhentos reais, e no mais eu fui vendendo aqui umas paradas, vendi moto, vendi violão, juntei uma grana. [...] No mais foi isso, a prefeitura infelizmente não investiu nada, não nos deu apoio nenhum. Aí teve uma galera da comunidade que se uniu assim [...] aí tipo um amigo que vinha trazia um pouco de comida, uma fruta, e a gente foi juntando e ficamos aqui seis dias mais ou menos de gravação (informação verbal). ${ }^{13}$
\end{abstract}

Em sua fala, também se evidencia um forte componente de solidariedade entre os habitantes de sua localidade que procuraram oferecer auxílio do modo como puderam para ajudar na produção do curta, elemento também presente no relato anterior de José Dhiones que, para baratear custos com alimentação da equipe, deixou a tarefa por conta de seus familiares. Nesse sentido, a produção dessas obras não se restringe apenas à equipe técnica em si, mas abrange outros atores como amigos e familiares dos próprios diretores que buscam oferecer auxílio direta ou indiretamente no processo.

Assim, esse componente afetivo acaba evidenciando-se como uma chave compreensiva importante para entender esses novos arranjos produtivos de cinema no interior do estado, o que acaba também por abranger a experiência cinematográfica (ainda em sua fase de produção) para outras pessoas da localidade, como familiares, amigos e demais habitantes. Vejamos como exemplo as filmagens do curta Caetana (2018), na qual o diretor conseguiu mobilizar metade dos habitantes da zona rural onde mora para participarem do filme, que se dividiram em várias tarefas desde a figuração/encenação até alimentação e transporte durante os dias de locação:

[...] foi muito massa também por que a gente pôde colocar todo mundo aqui do sítio, eu moro numa zona rural com cerca de 50 a 60 habitantes, destas, 30 pessoas estavam no filme. Enfim acho que foi isso assim, foi todo na camaradagem mesmo todo mundo se uniu [...] pra cozinhar pra essa galera

${ }^{13}$ Informação fornecida por Caio Bernardo em entrevista feita por mim em 16 de abril de 2019. 
foram pessoas que atuaram no filme, minha mãe, a mulher do meu tio, elas cozinhavam e ficavam se revezando, quando precisava atuar ou fazer alguma figuração, elas vinham e foi isso, o transporte utilizado era o carro de meu pai (informação verbal). ${ }^{14}$

Essa relação poderia apresentar um aparente paradoxo, pois, se do ponto de vista das condições materiais, evidencia-se um cenário marcado pela precariedade e escassez de recursos e equipamentos, em contramão a essa realidade temos uma rica produção com filmes de qualidade excepcional, que pode ser confirmada pela boa recepção que estas obras vêm tendo ao longo dos anos, sobretudo a partir da sua circulação/premiações via festivais pelo Brasil e no exterior:

A descentralização da produção tem demonstrado com êxito a força da produção no interior do estado. Esse processo caminha ao lado da evolução tecnológica e dá visibilidade à produção da Paraíba em festivais de cinema renomados, com críticas positivas aos trabalhos desses novos realizadores (ROLIM, 2017, p. 64).

Os dados de circulação trazidos aqui demonstram que esses jovens interioranos têm se apropriado dessas janelas de exibição, o que figura como uma estratégia no campo da divulgação/legitimação de suas obras. Essas táticas, de certo modo, também são mediadas pela tecnologia, haja vista que o que possibilita esse fluxo de troca e envio de obras artísticas para diversos lugares são as plataformas digitais.

Essa aparente contradição pode ser entendida a partir dessas novas configurações em que o dilema escassez versus quantidade pende para este último na contemporaneidade, em que os meios técnicos que garantem a criação em audiovisual estão cada vez mais acessíveis, o que permite um processo de utilização criativa dessas tecnologias a partir do cinema por jovens do interior do estado, permeado por novos arranjos do cinema brasileiro contemporâneo pensado a partir de estratégias, alternativas e modos de organização que se formam à base de coletivos frente a conjunturas marcadas pela falta de recursos, e que nos levam a assumir uma posição de combate ("guerrilha") visando realizar a sua obra cinematográfica.

Contudo, a exaltação feita a esse tipo de produção que consegue sobreviver em um ambiente marcado pela precarização das condições materiais e à revelia de incentivo por parte do Estado deve ser feita aliada a um olhar crítico, ou seja, no mesmo espaço é

\footnotetext{
${ }^{14}$ Informação fornecida por Caio Bernardo (idem).
} 
possível fazer esse elogio às capacidades criativas e de resiliência de produção e circulação desses bens, mas é preciso tomar cuidado para que isso não encubra o contexto de deficiência, falta de incentivo e fragilidade nas relações de trabalho (BENTES, 2012).

Nesse período, que vai de 2011 até o primeiro semestre de 2019 (tempo em que produzi a pesquisa que originou este artigo), aconteceram dez edições do laboratório Jabre, envolvendo 45 cidades da Paraíba, com um total de 121 participantes envolvidos diretamente nas ações do projeto e com saldo de 13 produções fílmicas de curta-metragem produzidos.

Nesse recorte, houve circulação e participação de integrantes do Jabres e de suas produções em festivais e mostras de filmes locais, regionais, nacionais e internacionais. ${ }^{15}$ $\mathrm{Na}$ Paraíba, foram 24 festivais e mostras (ocorridos em 14 cidades paraibanas); regionalmente, a participação se deu em 25 festivais e mostras (ocorridos em 32 cidades nordestinas); fora do Nordeste, foram 51 eventos (envolvendo 36 cidades brasileiras); internacionalmente (envolvendo 13 cidades da América do Norte, América do Sul e Europa), a participação se deu em 13 eventos. Tem-se, então, um total de 113 participações em eventos que ocorreram em 95 cidades, distribuídas em 8 países (incluindo o Brasil).

Em decorrência das participações indicadas, temos o quadro de premiações obtidas abaixo:

\begin{tabular}{|ccccccc|}
\hline \multicolumn{5}{|c|}{ Quadro 01 } & PREMIAÇÕES OBTIDAS PELO JABRES NO PERÍODO DE JANEIRO DE 2011 AO PRIMEIRO \\
Evento & Melhor curta $^{16}$ & Melhor roteiro & Melhor direção & Demais prêmios $^{17}$ & Total \\
Local & 42 & 13 & 15 & 55 & 125 \\
Regional & 14 & 3 & 3 & 30 & 50 \\
(Nordeste) & 11 & 2 & 4 & 15 & 32 \\
Nacional & 1 & - & - & - & 1 \\
Internacional & 68 & 18 & 22 & 100 & $\mathbf{2 0 8}$ \\
Total & & & & & & \\
\hline
\end{tabular}

Fonte: elaborado pelo autor a partir do material da pesquisa.

\footnotetext{
${ }^{15}$ Festivais e mostras que tiveram mais de uma edição foram contabilizadas apenas uma vez.

${ }^{16}$ Reúnem-se aqui os prêmios de melhor curta; melhor ficção; e melhor documentário nas categorias de prêmio da crítica, prêmio do júri oficial, prêmio do júri popular, melhor filme paraibano e nacional.

${ }^{17}$ Melhor direção de arte; melhor ator/atriz; melhor montagem; melhor fotografia; melhor som; melhor figurino etc.
} 


\section{Considerações finais}

A partir da aproximação proposta nesse trabalho entre autoria, cinema e processos criativos fomentados pelo Laboratório Jabre para Jovens Roteiristas, algumas considerações se fazem necessárias. A primeira delas, e mais clara, é que o laboratório funciona como uma porta de entrada que possibilita a esses jovens terem vivências das mais diversas mediadas pela linguagem cinematográfica, tanto a partir da apreciação da produção (prioritariamente paraibana) já existente, mas, sobretudo, por meio do encorajamento para que eles e elas ocupem posição de destaque como diretores/roteiristas, possibilitando assim uma experiência de autoria que é mobilizada a partir de diversas frentes.

Esse percurso que se inicia com o laboratório tem desdobramentos que abrem margem para outras experiências e cenários, seja a partir dos processos de filmagem e montagem dos curtas, seja também a partir da circulação via festivais pelo Brasil e pelo mundo. Essas experiências acabam por trazer mudanças significativas na vida e trajetória desses/as jovens interioranos/as, e contribuem para que tenhamos, hoje, uma cena de produção cinematográfica paraibana mais diversa e descentralizada.

Nesse sentido, pode-se dizer que a produção de audiovisual interiorana na Paraíba segue uma tendência mais ampla do panorama de cinema contemporâneo independente nacional. De todo modo, por trás dessas estratégias pautadas pela inovação técnica, e pela precariedade material, desvela-se um cenário marcado pelo potencial acessível do cinema digital e dos arranjos afetivos e descentralizados de produção contemporânea, mas também evidencia, pelo menos na Paraíba, um certo descaso do poder público no que se refere à ausência de fomento à cultura.

Esses resultados representam, sem dúvida, um ponto de virada em relação às décadas anteriores, quando a produção era limitada apenas a poucas cidades do estado. Sem dúvida, um cenário resultante da pouca capilaridade e escoamento de formação em cinema, mas também da falta de meios técnicos de gravação que possibilitassem produzir audiovisual nessas localidades. Na primeira década dos anos dois mil, houve já avanços de interiorização voltados principalmente para a introdução da linguagem cinematográfica nesses espaços por meio de oficinas e mostras de curta-metragem, o que, 
de certo modo, "adubou" o caminho para que posteriormente houvesse um impulso de produção cinematográfica nessas pequenas cidades.

\section{Referências}

BENTES, Ivana. Redes colaborativas e precariado produtivo. In: Periferia, Duque de Caxias - RJ, v. 1. n. 1, p. 53-61, 2012. Disponível em: https://doi.org/10.12957/periferia.2009.3418. Acesso em: 05 jun. 2021.

BERNARDET, Jean-Claude. O que é cinema. São Paulo: Brasiliense, 2000.

BRASIL. Medida provisória n 2.228-1 de 06 de setembro de 2001. Braślia, DF: Presidência da República, [2001]. Disponível em: http://www.planalto.gov.br/ccivil_03/mpv/2228-1.htm. Acesso em: 06 jun. 2021.

DE LUCA, Luiz Gonzaga Assis. A hora do cinema digital: democratização e globalização do audiovisual. São Paulo: Imprensa Oficial, 2009.

GALVAO, Maria Rita. O desenvolvimento das ideias sobre cinema independente. In: CINEMATECA BRASILEIRA. Cadernos da Cinemateca. São Paulo: Fundação Cinemateca Brasileira, 1980, p. 13-23. (v. 4).

GIDDENS, A. As consequências da modernidade. São Paulo: Editora Unesp, 1991.

IKEDA, Marcelo; LIMA, Dellani. O "cinema de garagem" e seus campos éticos, estéticos e políticos. In: IKEDA, Marcelo; LIMA, Dellani. (Orgs.). Cinema de garagem: panorama da produção brasileira independente do novo século. Rio de Janeiro: WSET Multimídia, 2012, p. 714.

HARVEY, David. Condição pós-moderna: uma pesquisa sobre as origens da mudança cultural. 13 ed. São Paulo: Edições Loyola, 2004.

JAMESON, Frederic. A lógica cultural do capitalismo tardio. In: JAMESON, Frederic. Pósmodernismo: a lógica cultural do capitalismo tardio. São Paulo: Editora Ática, 2007, p. $27-79$.

JOEL, Torquato. Quando as bordas viram centro. Trabalho de conclusão do curso de gestores cultuais. Fundação Joaquim Nabuco e UFRPE, 2014. Mimeo.

MICHETTI, Miqueli. Coletivos e redes culturais no Brasil contemporâneo: notas sobre as relações entre cultura, economia e política na conjuntura neoliberal. Arquivos do CMD, Brasília, v. 5, n. 1, p. 63-79, 2017. Disponível em: https://doi.org/10.26512/cmd.v5i1.8967. Acesso em: 05 jun. 2021.

MIGLIORIN, Cezar. O que é um coletivo. In. BRASIL, André. (Org.). Teia 2002 - 2012. Belo Horizonte: Universo, 2012, 307-313.

MIGLIORIN, Cezar. Por um cinema pós-industrial: notas para um debate. Revista Cinética, Online. 2011. Disponível em: http://www.revistacinetica.com.br/cinemaposindustrial.htm. Acesso em: 05 jun. 2021.

OLIVEIRA, Maria Carolina V. "Novíssimo" cinema brasileiro: práticas, representações e circuitos de independência. São Paulo: FFLCH/USP, 2016. (Série produção acadêmica premiada). 
Disponível em: http://spap.fflch.usp.br/sites/spap.fflch.usp.br/files/DO_Maria\%20Carolina\%20 Vasconcelos\%20Oliveira.pdf. Acesso em: 06 jun. 2021.

PINTO, Pedro Henrique Pinheiro Xavier. Imagens de si e dos outros: os Festivais Cinecongo, Festissauro e Curta Coremas como janelas de exibição para o audiovisual no semiárido paraibano. 2017. Tese (Doutorado em Sociologia) — Universidade Federal da Paraíba. João Pessoa, 2017.

ROCHA, Glauber. Uma estética da fome. Revista Civilização Brasileira, ano 1, n. 3, p. 165-170, 1965.

ROLIM, Cristiane Lucena. Estratégias alternativas de produção no cine brasileiro contemporâneo: o caso da cooperativa filmes a granel. 2017. Dissertação (Mestrado em Comunicação e Culturas Midiáticas) — Universidade federal da Paraíba, João Pessoa, 2017.

SILVA JUNIOR, Edmilson Gomes da. Do laboratório à autoria: Projeto Jabre e experiência cinematográfica no interior da Paraíba. 2019. Trabalho de Conclusão de Curso (Licenciatura em Ciências Sociais) - Universidade Federal da Paraíba, João Pessoa, 2019.

SILVA, Virgínia de Oliveira. Duas experiências de cinema e educação no estado da paraíba. Internet Latent Corpus Journal, Aveiro/Portugal, v. 5, n. 1, p. 52 - 65, 2015a. Disponível em: https://doi.org/10.34624/ilcj.v5i1.14725. Acesso em: 07 jun. 2021.

SILVA, Virgínia de Oliveira. Educação (in)formal em cinema na Paraíba. In: REUNIÃO NACIONAL DA ANPED, 37., 2015, Florianópolis. Anais [...]. Florianópolis: UFSC, 2015b. p. 115.

Recebido em: 23/05/2021.

Aceito em: 24/05/2021. 